\section{"II CONGRESSO PANAMERICANO DE ESCOLAS DE HOTELARIA E TURISMO" SOB A OUTICA DE UM PARTICIPANTE}

\author{
José Ruy Veloso Campos'
}

\begin{abstract}
RESUMO: Apresentação dos principais lópicos c discussōes do ll Congresso Panamericano de Esccolas de Hotelaria c Iurismo. rcallyado $\mathrm{cm}$ Buenos Aires, de 24 a 28 de sctembro de (א)2. Ressalta o sistema de educação em turismo nos Isstados Unidos. aprescntado pela repiescntante da George Washington University. alćm de sintcsc de outras apresentaçes c discussõcs. Sob o ponto de visti de un panticipantc. países da América l atina.
\end{abstract}

PALAVRAS CHAVI:: Turismo c l lotclaria: cducacão. cscolas páname ricanas.

ABSTRACT: Prescrtation of the main topics and discussions: of the It Panamerican Comgress on Hold Busincss and Tontrism Schorls. held in Buenos Aircs, from Scptember 2f to 28, 1962 2. limphasizes the toursm cducation sustem in the United States, prescented he the reperescinturive of the Gcorge Washington Universing, besides symberising other comferences and

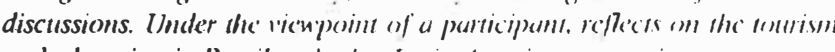
and cducation in Brazil and other I.atin Amcrican commerics

KEY WORDS: Tourism and Hord lBusiness: caftucation, panamerican schools.

1 Bacharel em Letras c Pósgraduandu cm Marketing. Dirctor do (ILATILI - Centro de Estudos de Administração cm Turismo e Hotclaria -. instituição de nivel superıor mantida pelo SENAC de São Paulo. Consultor em Administracão Hotelerra Vice-Presidente da ABDIHIT - Associaça Brasilcira de Dirigcntes de Fiscolas de Hotelaria e Turismo.

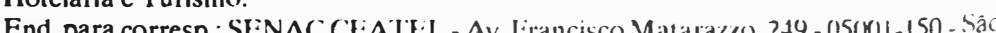
Paulo - SP - Brasil.

\section{INTRODUÇA()}

O II Congresso Panamericano de Escolas de Holclaria e Turismo ${ }^{2}$ que aconteceu e'm Bucmos Aires, no períndo de 24 a 28 de selembro de 1992, conseguiu reunir mais de 40 representantes dos seguintes países: Canadá, Estados Linidos, México, Costa Rica, ( uba, Répública Dominicana, Nicaragua, Panamá, Equador, Perú, Colômbia, Chilc, Brasil, Uruguai, Paraguai e Argentina. Diferentes comissoes discutiram vatrios assuntos, como a questào dos currículos e perlis profissionais que devem orientar as escolas para aprimorar a formaçăo de seus alunos.

Este texto apresenta, de forma sintética, os principais tópicos e discussões desse evento, destacando a exposiçac) da professora Sheryl Spivak, da George Washington University, que apresentou uma "radiografia" da educaçāo em turismo nos Estados Unidos.

\section{TURISMO NO SISTEMA DE EDUCAÇÄ()SUPERIOR NOS ESTADOS UNID(OS}

O tema apresentado pela representante da (jeorge Washington University, professora Sheryl Spivak, levantou os aspectos que alavancaram o turismo interno nos Estados Unidos, sohrctudo nos últimos cinquenta anos, como suporte para a maior circulaçäo de pessoas graças à legislação que melhor definiu os períodos de férias.

Ela citou que, scgundo o Departamento de Estatísticas do Trabalho, calcula-se que o emprego, só na indústria dous serviços de alimentação, aumentará $32 \%$ de 1982 a 19\%5, comparado com o aumento de $25 \%$ em outras ocupaçoes. A demanda por gerentes de serviços de alimentos aumentará $47 \%$ no mesmo período. A demanda por chefes de cozinha também deverá crescer na mesma proporçāo c a de gerentes hotcleiros mais rapidamente do que todos os empreges em geral.

A demanda de trabalhadorcs para a indóstria do lurismo continua crescendo, enquanto a força de (rabalho decrescec, devido à mud.unça demográfica. Isso deve perdurar até a metade da década de 1990. Essá combinação do crescimento da indústria e a falt a de pessocoal qualificado levou à criação de um sistema de educaçào de turismo pós-secundário.

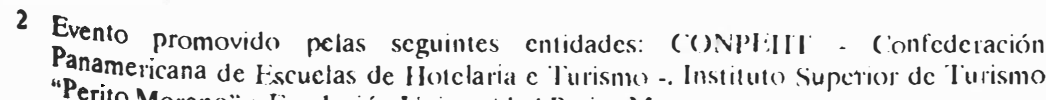
"Perito Morcno" e Fundación Universidad Pcrito Morcno. 
Compreendendo que atualmentc a cducação norte-amcricana está voltada para o pós-secundário, finalizar o "High School" é mais regra do que excessão: $75 \%$ dos jovens americanos finalizam o "High School"3 comparados com 50\% em 194(). A classe média-alta amcricana valoriza e busca o nível superior.

O primeiro programa universitário relacionado ao turismo foi criado pela Cornell University em 1922. Setenta anos depois, em 1992, mais de 700 programas oferecem títulos e certificados cm turismo. ()utros 170 programas entre Canadá c Estados Unidos outorgam título de bachare. lado ("Bachelor Degree") ${ }^{4}$ em educação sobrc Hospitalidade c Turismo.

Enquanto nas últimas décadas o foco dos programas cra no nível operacional e sem formação universitária, em meados da década de 1980 o foco das programaçōes tende para o nível acadêmico. Em ambess os casos, nível universitário ou não, os programas contemplam mais a área de hospitalidade. ()s "community colleges"5 oferecem programas preparando pessoas para administração de hotćis, restaurantes e agências de viagem.

Desse modo, a educação turística está dominada por currículos voltados a operaçōes. A demanda crescente por empregos com maior instrução levou os programas para graduados se desenvolverem, proporcionando a experiência profissional requerida por esses tipos de carreiras.

Em nível universitário sào 29 as universidades do ('anadá e Estados Unidos que oferecem o "Master Degrec" cm Hospitalidade e Turismo, predominando o título de Direçāe de Hospitalidade. Nessas instituiçōes encontram-se áreas que inclucm administração de hotéis, direção de serviços de alimentos, cducação supcrior $\mathrm{em}$ administração, direção em hospitalidade, ciência da manutenção, ccologia c recursos humanos.

O Turismo não está incluído como áréa de estudo por nèn/uum desses estabelecimentos. É considerado como doutorado $\mathrm{cm}$ área de especialização em três universidades: "George Washington" (Washington), "Virginia Polytechinic Institute and State University" (Biacksburg, Virginia) e "University of Calgary" (Calgary, Canadá). No entanto, o pequeno número de doutorados não impediu o crescimento do turismo como uma

3 "High School": último ciclo do cnsino secundário nos Iistados Únidos. () cicto todo compöe-se de: "Elementary School" (6 anos): "Jr. High School" (3 anos) e "High compóe-se de: "'
School" ( 3 anos).

4 "Bachelor Degre": nivel universitáro com 4 anos de duração.

5 "Community College": fundaçōes mislas das comunidades (a nível público e privado). que oferecem programas de curso supcrior com duração de 2 anos. de teses já aceita. Nos últimos quarenta anos surgiram 129 teses que area detes as palavras viagem. unismo c turista.

No entendimento da professora Sheryl Spivak, o turismo é uma fissão nascente. Isso é demonstrado pela litcratura pouco extensa profissa nasto. () número de disciplinas que "engrossa" a literatura nessa sobreo assunto a massa de conliccimento possa não scrvir como marco área suger para a profissão. Enquanto iumenta o número de publicaçōes é preciso observar a qualidade do matcrial, idoncidade editorial etc. Um é preciso obser apontou três publicaçōes sobre turismo e hospitalidade estudo recente apontou tre Annals of Tourism Research, The Comell Hotel and Restaurant Quarelv c Thu Joumbal of Travel Research. Dos três, só a and Restaurant Quída èm um índice crudito.

O turismo é visto, por muitos profissionais c acadêmicos que não são da área, como controvertido, complexo, variável, simplista c pouco claro. Mesmo como área acadêmica de estudo é questionada por acadêmicos pouco informados sobre o lema. Apesar disso tudo, tem sido uma próspera área de estudo c uma accitável árca de investigação para acadêmicos em várias disciplinas.

Um outro tópico que a representante dos Estados Unidos abordou é que o turismo não $t \mathrm{~cm}$ uma hase tcórica universalmente accita. Essa base é necessária porque o scu desenvolvimento como disciplina acadêmica produz efeitos no necio pclo yual sc organiza a massa de conhecimentos, no modo pelo qual se translere a habilidade e o conliecimento técnico, e no crescimento do pensamento intelectual.

Existe desacordo quanto ao marco tcórico, o diecr disciplinário, interdisciplinário e multidisciplinário, que formaria a basc do turismo como área acadêmica de estudo. Há também a falta de acordo quanto a uma terminologia básica. E, ainda, o corpo docente pouco especializado no assunto: as titulaçōes mais diversas compōem o quadro de professores com a especialização cm áreas acadêmicas comuns a out ras disciplinas e, as vezes, sem nenhum conhecimento sobre turismo.

A professora Spivak foi enfática: "a falta de preparo específico de docentes é a causa da grande inconsistência tcórica e tcrminológica que tem atrasado o turismo como área acadêmica c como profissão". Propôs que sejam desenvolvidos docentes em nível de doutorado, uma abcrtura recente nos Estados Unidos. Em todo o país, somente cinco) acadêmicos receberam título de Doutor com Especialização cm Turismo entre 1988 e 1989 e, quatro entre 1983 c 1985. Espera-sc que os acadêmicos estcjam mais estimulados a obtcr essc (ítulo, com o que contribuirão para aumentar a massa de conhecimentos, publicaçōes etc 


\section{CANADÁ QUER IMATEM}

A falta de uma base de conhecimentus teóricos náo impede, contudo, o aumento da oferta e demanda nos cursos de turismo, segundo 0 representante do (anadá, professor Jcan (laude Pageot, de ()tlawa. O turismo é a terceira indústria naquele país, vendendo neve quase o ano inteiro, todo o tipo de eco-sistema, parques nacionais, limpera, segurança e baixa densidade demográfica. () ('anadá recele dois grupos principais de turistas: os que procuram cullura e natureza c os que buscam hislória e cultura local. Esse último grupo ć formado por pessoas com mais de 50 anos que viajam em grupo de aproximadamente 10 pessoas.

O governo deve criar, nos próximos anos, mais de 18 parques terrestres e 8 marinhos. Vai também recuperar as vias férreas ahandonadas juntamente com o setor privado e criou a Transcanadensc. () esforço maior, no entanto, situa-se na criaçāo de pequenos hotćis. Exisic ainda um Plano Nacional Verde, com capítulos de vida ativa e meio-ambiente, para o qual foram destinados 12 milhōes de dólares para os próximos 5 anos. As instituiçōes oficiais priorizam a investigaçāo, os projetos pilotos, as modalidades alternativas de transporte, os programas associando bicicletas ao transporte público, os passcios livres oferecidos aos turistas pelo serviço público e a melhoria do estilode vida canadense para atrair mais turistas.

Em 1982 existia 1 curso c 12 cstudantes; em 1992, 18 cursos e 360 estudantes.

\section{TURISMO DE SAÚDE}

O paincl Turismo de Salide, composto por integrantes do Canadá, Cuba, Argentina e Uruguai, discutiu o real papel dos" Spa's"' c outros tipos de tratamento que vāo das clínicas de repouso ao tratamento específico do vitiligo ${ }^{7}$. Considerou-se que a tendência do "Spa" e outras clínicas é a popularìaçāo c atcendimento para outras calcgorias que nāo estão na ponta da pirâmide social. Tem-se como certo que no próximo século, mais de $80 \%$ das doenças scrào decorrentes do estilo de vida, considerando-se a populaçāo economicamente at iva.

6 "Spa's": denominaçāo dada. no Brasil. anos holćis que sc cspecialıaam con tratarnemto de emagrecimento e rejuvenecimento. Nome original da cidade de Spa Francorchanp. na Bélgica.

7 Vitiligo: S. M. Vitiligem. Vitiligem: afcçăo cutâncit caractervzadal por zon-ss de despigmentação.
Nesse painel surgiram dados importantes sobre a manipulação de alimentos:

os países andinos são hoje perscguidos pelo fantasma do cólera; os pado, mesmon na América do Norte existem casos de gastroenterite contudo, mescāo de grandes grupos;

em alu dados dos painelistas, ocorreram sćrios casos de intoxicação;

b) segundo Caribe, por cxcmplo, $1(1) 0$ pessoas foram contaminadas com um no Caribe, caracol marinho;

tipo de 1947 e 1984, os casos de pessoas que, nos Estados Unidos, sofreram intoxicaçāo apresentou o scguinte percentual: por frios $(14 \%)$, quentes $(4 \%)$, entradas $(6 \%)$, saladas $(2 \%)$, cremes $(4 \%)$ e outros $(69 \%)$; mortc ( $1 \%)$;

d) cruzeiros marítimos de 3 a 15 dias com um mínimo de 100 pessoas registraram, entre 1975 a 198.5, 4.5 intoxicaçocs; os frutos do mar foram responsáveis por 8 casos $\mathrm{e}$ lagosta por 1 caso.

O entendimento dos participantes é o de que as escolas de hotelaria devem investir nos programas de manipulação de alimentos, sobretudo nos países do tercciro mundo, para os quais a (Organizaçāo Mundial de Saúde recomenda tratamento parasitológico preventivo, em ravāo das condiçōes gerais de moradia do pessoal de serviços de base, do alto custo dos exames laboratorais e da constante necessidade de repetiçāo desses exames.

\section{HOTÉIS-ESCOLA}

Uruguai, Argentina, México, Brasil, Colômbia, República Dominicana, Cuba, Equador e Peru discutiram a necessidade de hotcl-escola e sua funçāo no preparo de profissionais para o setor de turismo.

O hotel-escola ć aceito e entendido como um emprecndimento qualquer que possa subsidiar um atividade educacional. Para tanto, é preciso que os seviços operacionais de atendimento ao hóspede scjam realizados por profissionais que monitorem os alunos $\mathrm{cm}$ estágio de aplicação.

A tendência geral das escolas é a de estabelecer convênios com hotéis comerciais, mantendo uma estrutura de escola paralcla ao hotecl, e utilizando-o como campo de aplicação e estágio. As empresas hotelciras têm dificuldades de entender é ajudar nessa ação.

O Brasil tem os melhores holćis-cscola da regiāo sul c a sugestāo foi a de um intercâmbio de formadores c alunos. A língua portugucsa é ensinada nos cursos de Turismo e Hotclaria dos países do Mercosul. As 
escolas brasileiras deverão, em contrapartida, adotar o cnsino do espa. nhol em seus cursos c preparar seus docentcs em língua espanhola.

Os países andinos sugeriram um acordo sub-regional de comple. mentaçāo e troca de bolsas c intercâmbio de estudantes quic possam e se interessem em receber colegas latinos $\mathrm{cm}$ suas residências.

A observaçāo de representantes do Brasil foi relativa aos cuidados necessários na internacionalizaçāo versus regionalizaçāo de costumes e tradiçōes, aplicados à cozinha e atividades diversas do turismo. A proposta é de universalizar o perfil mantendo as características locais, e trabalhar na investigaçāo e preparo de material para favorecer a formaçāı) de quadros de base. Por esse raciocínio ć importante a rclaçāo da universidade com as comunidades de vocaçāo turística e empresas de modo geral, no sentido de vender aos orgãos (públicos c privados) os serviços que a comunidade acadêmica possa prestar, com base em investigaçōes e experiências realizadas por seus professores $\mathrm{e}$ alunos.

Para que o Turismo seja desenvolvido em países pobres, é preciso que o conhecimento acadêmico vá ao campo cm interaçāo com quem presta os serviços ao turista. Em outras palavras, ć preciso "desemparedar" o saber.

\section{HISTÓRIA E GEOGRAFIA}

A comissāo de História concluiu que nessa área é preciso trabalhar partindo do presente mas buscando no passado as raízes da atualidade retrospectivamente. É preciso construir uma História que rompa com a visāo de que tudo se fundamenta em datas num contexto às vezes desconexo. Defendeu-se uma História culturalista, que habilita para a convivência social e ajude a superar os prejuízos.

A unidade Ibero-Americana deve alicerçar-se nesses princípios e aceitar as diferenças e as diversidades culturais. Nesse sentido recomendou-se o intercâmbio de docentes e alunos entre as instituições, e cursos de integraçāo.

O grupo de Geografia concluiu que os programas devem partir de um modelo de turismo receptivo, onde cada país tenha uma imagem clara de seu produto turístico para vendê-lo. Isso significa um processo de ensino que vê do local ao universal. No ensino universal ć necessário estudar aqueles destinos mais significativos de cada regiāo turística mundial, enfatizando a regiāo latino-americana. É preciso, ainda, considerar o mercado turístico como uma realidade dinâmica, onde os destinos podem variar em sua im

As matérias de (icografia Turstica deverāo incluir critérios de análise de espaço integral, estudando os distintos fatores condicionantes (sociais, políticos, econômicos e ambientais). ()s conteúdos deverāo levar em conta uma sólida preparação teórica, dando especial atenção à localizaçāo, análise de recursos físicos e humanos como atrativos turísticos, c à realizaçāo de práticas contínuas em campo.

\section{COMPATIBILIZAÇÃO DE CURRÍCULOS}

A adequaçāo de programas de cursos para os países do Mercosul e outros da América Latina foi uma discussāo difícil. () México, por exemplo, tem seu foco na administraçāo hotelcira, onde cstá o forte de sua açāo turística. A Costa Rica, parte da Argentina e países andinos fazem do turismo de aventura o seu grande produto. As sugestōes apontaram para o desenvolvimento de complementaçôes a nível regional para os cursos de diversos países, e a criação de certificado pela (C)NPEHT, que possibilite abertura para os egressos de escolas americanas em qualquer país.

\section{REFLEXỎES SOBRE A EDUCAÇÃO EM TURISMO E HOTELARIA NA AMÉRICA LATINA}

A riqueza de um congresso dessa nat ure\%a reside certamente na grande troca de bagagem e experiências específicas de cada instituiçāo participante. O Brasil, por exemplo, o maior c mais rico dos "hcrmanos" latinos, está longe de ser o melhor organizado nessáa área: nāo tem projetos privados ou governamentais a médio ou longo praz.), no plano ambiental, por exemplo.

Do ponto de vista acadêmico, as facilidades disponíveis para os alunos se afiguram como outro problema $\mathrm{em}$ alguns países. Começando por universidades que se limitam a aulas tcóricas e pouco promovem ou estimulam açōes práticas para os estudantes de turismo, atć escolas de hotelaria que formam técnicos $\mathrm{em}$ gastronomia sem ter cozinha, há muito - que buscar na realizaçāo de propostas educacionais nesse setor.

É conhecido que descasos dessa natureza nāo ocorrem somente na área de Turismo. Tampouco são os filhos das clites que frcqücntam as salas de aula de turismo e hotelaria. Contudo, é preciso ficar atenlo às observaçōes da representante da Universidade (icorge Washington sobre a base de conhecimentos na área. É preciso que as instituiçôes zelem por seu trabalho e por seus alunos; convivam com a relidade das comunidades de vocaçāo turística e saiam a campo para auxiliá-las a plancjarem-se, formar seus agentes e melhorar a lace dessa atividaertânesiâmica a partir dos municípios, da base da sociedade. 
Se nāo houver uma interveniéncia desses "de positirios do conhecimento" na açāo efetiva para a melhoria do Turismo, o que esperar? - A ação dos governos centrais endividados, que náo dáo conta das necessidades sociais básicas? Continuar formando pessoloas que vào continuar buscando trabalho e melhorias no sctor?

As instituiçōes devem ir às bases ofereecer seu conhecimento e formar parceria para alavancar of urismo c valorivar seu (rahalho, a irca, o aluno e, sobretudo, o nativo em sua comunidade. Alirmaçoès dessa natureza podem soar estranhas aos acadêmicos mais conscrvadores. Contudo, o final do século $X X$ vem sendo marcado por revoluçōes fantásticas com o grande suporte dos veículos de comunicaçāo c informação, que exigem das instituiçôes de educaçāo, mais do que atualizaçāo, uma revisāo no seu comportamento frente às realidades que se apresentam e estāo a exigir análises constantes. Com isso, partindo-se, de registros de dados históricos e acadêmicos, poder-se-á contribuir muito de perto para melhorar os destinos de naçōes que tiveram ao longo de séculos suas soberanias aviltadas e sua cultura massacrada pelo colonialismo.

Trabalhar com Educaçāo em Turismo na América Latina significa ter presente questōes como essas no cotidiano das instituiçóes c de seus professores. 